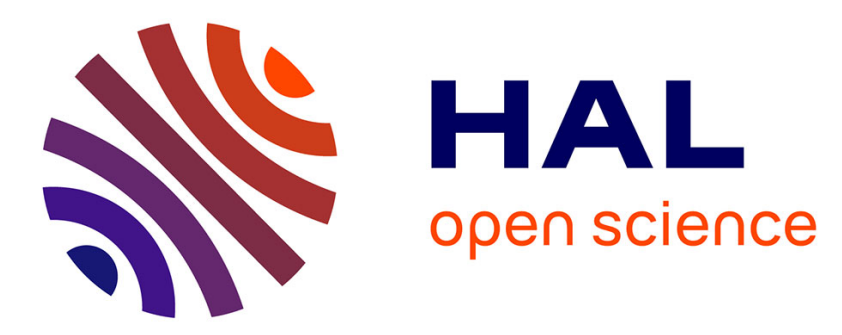

\title{
Serum concentrations of paliperidone versus risperidone and clinical effects
}

\author{
Yasmin Nazirizadeh, Friederike Vogel, Wolfgang Bader, Ekkehard Haen, \\ Bruno Pfuhlmann, Gerhard Gründer, Michael Paulzen, Markus Schwarz, \\ Gerald Zernig, Christoph Hiemke
}

\section{To cite this version:}

Yasmin Nazirizadeh, Friederike Vogel, Wolfgang Bader, Ekkehard Haen, Bruno Pfuhlmann, et al.. Serum concentrations of paliperidone versus risperidone and clinical effects. European Journal of Clinical Pharmacology, 2010, 66 (8), pp.797-803. 10.1007/s00228-010-0812-7 . hal-00582164

\section{HAL Id: hal-00582164 https://hal.science/hal-00582164}

Submitted on 1 Apr 2011

HAL is a multi-disciplinary open access archive for the deposit and dissemination of scientific research documents, whether they are published or not. The documents may come from teaching and research institutions in France or abroad, or from public or private research centers.
L'archive ouverte pluridisciplinaire HAL, est destinée au dépôt et à la diffusion de documents scientifiques de niveau recherche, publiés ou non, émanant des établissements d'enseignement et de recherche français ou étrangers, des laboratoires publics ou privés. 


\title{
Serum concentrations of paliperidone versus risperidone and clinical effects
}

\author{
Yasmin Nazirizadeh • Friederike Vogel • Wolfgang Bader • Ekkehard Haen • \\ Bruno Pfuhlmann • Gerhard Gründer • Michael Paulzen • Markus Schwarz • \\ Gerald Zernig • Christoph Hiemke
}

Received: 21 August 2009 /Accepted: 8 March 2010 /Published online: 1 April 2010

(C) Springer-Verlag 2010

\begin{abstract}
Purpose The major aim of this multicenter retrospective analysis was to examine the relationship between paliperidone serum concentrations and clinical effects in patients
\end{abstract}

Y. Nazirizadeh $\cdot$ F. Vogel $\cdot$ C. Hiemke $(\bowtie)$

Department of Psychiatry and Psychotherapy,

University Medical Center,

Johannes Gutenberg University Mainz,

Untere Zahlbacher Str. 8,

55131 Mainz, Germany

e-mail: hiemke@mail.uni-mainz.de

W. Bader $\cdot$ E. Haen

Clinical Pharmacology/Psychopharmacology

of the Department of Psychiatry,

Psychosomatic and Psychotherapy, University of Regensburg,

Regensburg, Germany

\section{B. Pfuhlmann}

Department of Psychiatry and Psychotherapy,

University of Würzburg,

Würzburg, Germany

G. Gründer $\cdot$ M. Paulzen

Department of Psychiatry and Psychotherapy,

RWTH Aachen University and JARA-Brain:

Translational Brain Medicine,

Aachen, Germany

M. Schwarz

Hospital for Psychiatry and Psychotherapy,

Ludwig-Maximilians-Universität,

Munich, Germany

\section{G. Zernig}

Experimental Psychiatry Unit,

Department of General Psychiatry and Social Psychiatry,

Medical University Innsbruck,

Innsbruck, Austria treated with this new antipsychotic drug. Intra-individual variability in trough serum concentrations was also analyzed in patients under treatment with either the paliperidone-extended release (ER) formulation or the risperidone immediate-release formulation.

Methods Data were obtained from 217 patients of four medical centers who were being followed by therapeutic drug monitoring (TDM). Serum concentrations were associated with clinical response using Clinical Global Impressions (CGI) scores.

Results The mean concentration of paliperidone was $36 \pm$ $25 \mathrm{ng} / \mathrm{ml}$, and the mean dose corrected concentration (C/D) was $4.7 \pm 2.9 \mathrm{ng} / \mathrm{ml} / \mathrm{mg}$. Among patients receiving paliperidone as antipsychotic monotherapy and who showed at least a much improved level according to the CGI scores, the 25th-75th percentiles of paliperidone concentrations were $20-52 \mathrm{ng} / \mathrm{ml}$; these were very similar to the recommended therapeutic range of $20-60 \mathrm{ng} / \mathrm{ml}$ for risperidone plus 9-hydroxy-risperidone (active moiety). In 13 patients treated with paliperidone ER and 17 patients treated with risperidone, all of whom had repeated drug measurements, the intra- and inter-individual variabilities of trough serum concentrations were similar for the paliperidone and risperidone active moiety, ranging between 30 and $35 \%$.

Conclusion Based on these results, we conclude that risperidone and paliperidone have a similar therapeutic range and similar intra-individual variability in terms of trough serum levels. For treatment optimization, monitoring of plasma concentrations may be as useful for paliperidone as for risperidone.

Keywords Antipsychotic drug - Inter-individual variation . Paliperidone · Pharmacokinetics · Risperidone · Therapeutic drug monitoring $\cdot$ Trough serum concentrations 


\section{Introduction}

Paliperidone is an atypical antipsychotic drug [1, 2]. It is identical to 9-hydroxyrisperidone, the pharmacologically active metabolite of risperidone, and has a similar pharmacological profile as risperidone, exhibiting high affinities for the dopamine $\mathrm{D}_{2}$ and the serotonin $5-\mathrm{HT}_{2}$ receptor [3, 4]. Paliperidone has been made commercially available as a new antipsychotic treatment option in an extended-release (ER) formulation using OROS technology from ALZA Corp (Vacaville, CA). This delivery profile allows treatment to be started with therapeutically effective doses without the need of initial dose-escalation for acceptable tolerability. The administration of paliperidone ER results in small 24-h peak-to-trough fluctuations in paliperidone plasma concentrations at steady state [5], thereby avoiding the rapid raise and fall in concentrations characteristic for immediate-release oral formulations. Since paliperidone does not undergo significant hepatic metabolism [6], it is also well tolerated by patients with poor hepatic function, and it is not susceptible to metabolic drug interactions.

Studies on the pharmacokinetics of risperidone have revealed large inter-individual variation in the concentrations of the active moiety risperidone plus 9hdroxyrisperidone [7]. Since the response to antipsychotic drugs needs sufficient $\mathrm{D}_{2}$ receptor blockade, which correlates well with the plasma concentrations of most antipsychotics [8], the efficacy and tolerability can be improved by therapeutic drug monitoring (TDM). For risperidone, it has been reported that concentrations of the active moiety of $20-60 \mathrm{ng} / \mathrm{ml}$ should be attained for optimal clinical outcome [9]. Because of almost identical pharmacodynamic profiles, the therapeutic range of paliperidone is expected to be identical to that of the risperidone active moiety. Data from patients which verify or refute this assumption, however, are lacking to date. The constant delivery formulation of paliperidone has a positive impact on peakto-trough fluctuations which may lead to a better tolerability and possibly explain why the usual daily doses of paliperidone are 6-9 $\mathrm{mg}$ and thus higher than those for risperidone (4-6 mg). It may also be expected that intraand inter-individual variations in drug concentrations in the blood are less pronounced in patients taking paliperidone ER than in those given risperidone.

In the study reported here, we analyzed serum trough concentrations of paliperidone in patients treated with paliperidone in association with clinical effects and compared the drug concentrations with those reported in the literature for risperidone $[10,11]$. For comparison, we also analyzed intra-individual variability in the trough serum concentrations in patients being treated with either the paliperidone ER formulation or risperidone.

\section{Subjects and methods}

Subjects

Data were obtained from patients of four psychiatric hospitals (Mainz, Munich, Regensburg, and Würzburg) between 2007 and 2009. Serum concentrations of paliperidone were recorded for treatment optimization by TDM. Blood was drawn under steady state conditions, namely, from patients who had been treated with paliperidone for at least 5 days, in the morning before the first dose of the day.

This naturalistic study was carried out in accordance with current German law (PsychKG), and retrospective analysis of TDM data was approved by the local Ethics Committee.

The Clinical Global Impressions (CGI) scale [item one, 1-8 points, for severity (CGI-S); item two, 1-5 points, for improvement (CGI-I)] was used to assess the patient's state [12]. Side effects were assessed using a modified UKU scale [13]. The CGI and UKU scores were rated on the day of blood sampling and entered into the request form for the TDM measurements [9].

Analysis of serum paliperidone and risperidone concentrations

Drug measurements were performed in four different laboratories of the TDM group of the Arbeitsgemeinschaft für Neuropsychopharmakologie und Pharmakopsychiatrie (AGNP, see: www.agnp.de). All four laboratories used chromatographic methods, and all were continuously checked using internal and external quality assurance programs to attain comparable results. The assay specifications, precision, accuracy, limit of detection, and linearity were similar in the different laboratories. Risperidone and paliperidone were determined by established highperformance liquid chromatography methods [14, 15]. For these assays, the inter- and intra-coefficients of variance were $<15 \%$. The limit of detection was about $2 \mathrm{ng} / \mathrm{ml}$ for both risperidone and paliperidone [14]. The quality of the analyses was controlled by participation in an external quality control program to assure similar results in different laboratories.

Statistical analysis

Data were given as arithmetic means with the corresponding standard deviation (SD). The inter- and intra-individual variabilities were given as the percentage coefficient of variance (CV\%) which was based on a minimum of three measurements. The Pearson correlation was used to determine the relationship between the daily dose of paliperidone, therapy improvement according to 


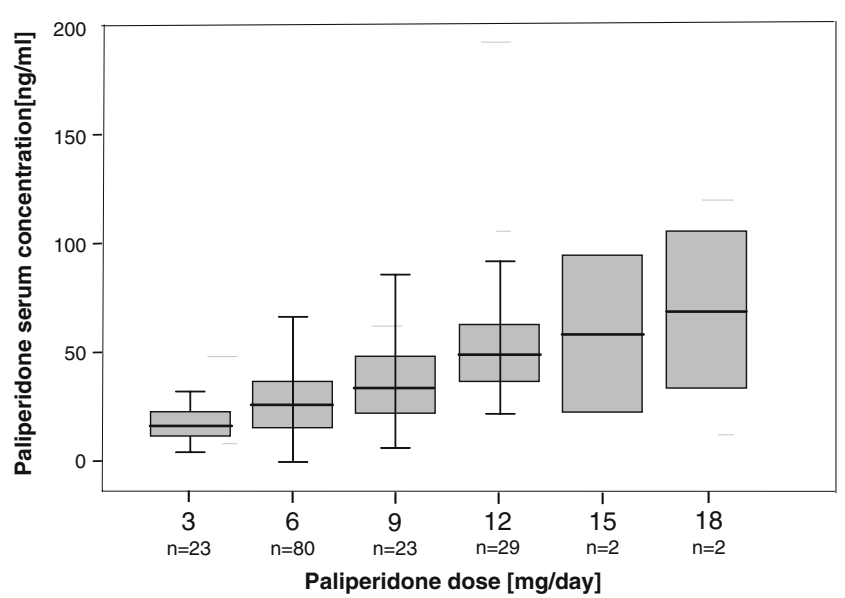

Fig. 1 Box plot of the correlation of paliperidone serum concentrations with the given dose

CGI-I, and the measured serum concentrations. Student's $t$-test and the Mann-Whitney $U$ test were used to determine statistical significance between groups.

\section{Results}

For paliperidone, we analyzed a total of 303 blood samples obtained from 217 psychiatric patients at four psychiatric hospitals (Mainz, $n=100$; Regensburg, $n=77$; Würzburg, $n=30 ;$ Munich, $n=10$ ). Among the 217 patients, $106(48.8 \%)$ were receiving paliperidone as antipsychotic monotherapy. We used the first measurement under steady state conditions for each patient. Complete information on treatment efficacy and co-medication was available for each patient.

According to the International Classification of Diseases, Tenth Edition (World Health Organization, ICD-10), most of our patients suffered from schizophrenia spectrum psychoses $(67.4 \%)$, with $16.4 \%$ suffering from a schizoaffective disorder, 5.2\% from a bipolar affective disorder, $6.1 \%$ from depression, and $3.8 \%$ from other psychiatric disorders. The patient cohort comprised $54 \%$ males and $46 \%$ females, with a mean age of $38.1 \pm 12.3$ (range 18-89) years.

The patients were, on average, markedly ill [CGI-S (mean $\pm \mathrm{SD}$ ) $5.9 \pm 0.9$ ] and showed highly variable responses to paliperidone treatment (CGI-I 2.6 \pm 1.0 ). The average number of additional medications administered to each patient was $2.4 \pm 2.0$ (range 0-8 concomitant medication).

The oral daily dose of paliperidone ranged between 3 and $18 \mathrm{mg} / \mathrm{day}$, and the mean daily dose was $7.8 \pm 2.9 \mathrm{mg} /$ day, which yielded a mean paliperidone serum concentration of $35.7 \pm 25.2 \mathrm{ng} / \mathrm{ml}$ (range $0-213 \mathrm{ng} / \mathrm{ml} ; 25$ th -75 th percentiles $19.5-46.0 \mathrm{ng} / \mathrm{ml})$. The mean dose-corrected paliperidone concentration $(\mathrm{C} / \mathrm{D}$, concentration/dose ratio) was $4.7 \pm 2.9 \mathrm{ng} / \mathrm{ml} / \mathrm{mg}$. The dose-dependent serum concentrations are shown as box plots in Fig. 1. The Pearson correlation between the prescribed daily dose and resulting serum concentrations was $r^{2}=0.452(p<0.001)$.

The mean serum concentration of paliperidone was $35 \pm$ $29 \mathrm{ng} / \mathrm{ml}(25 \mathrm{th}-75$ th percentiles $18-44 \mathrm{ng} / \mathrm{ml})$ in the 106 patients receiving paliperidone as antipsychotic monotherapy. Among the 63 patients for whom GCI scores of improvement were known, 32 were very much or much improved (Fig. 2). The mean paliperidone serum concentration of these patients was $43 \pm 39 \mathrm{ng} / \mathrm{ml}$ (25th-75th percentiles $20-52 \mathrm{ng} / \mathrm{ml}$ ). Among patients who showed minimal or no improvement $(n=31)$, the mean paliperidone serum concentration was $33 \pm 24 \mathrm{ng} / \mathrm{ml}$ (25th-75th percentiles $19-41 \mathrm{ng} / \mathrm{ml})$. Co-medications in patients receiving antipsychotic monotherapy with paliperidone included antidepressants (27\%), mood stabilizers (17\%), anxiolytic or hypnotic drugs $(31 \%)$, or non-psychiatric drugs $(38 \%)$. Drugs with an inhibiting or inducing potential on the cytochrome P450 3A4 (CYP3A4) isoenzyme, which is involved to some extent in the metabolism of paliperidone, were not present.

Analysis of the complete patient sample for side effects revealed that more than half of the patients $(62.3 \%)$ were free from side effects according to the physician's report (UKU scale), with 28\% developing mild adverse events, $8.5 \%$ moderate adverse events, and $1.5 \%$ severe adverse events. The most frequently reported adverse events were somnolence $(18.9 \%)$, extrapyramidal disorder $(16.8 \%)$, and agitation (3.2\%). There was no observable correlation between dose or serum concentrations of paliperidone and side effects (Fig. 3).

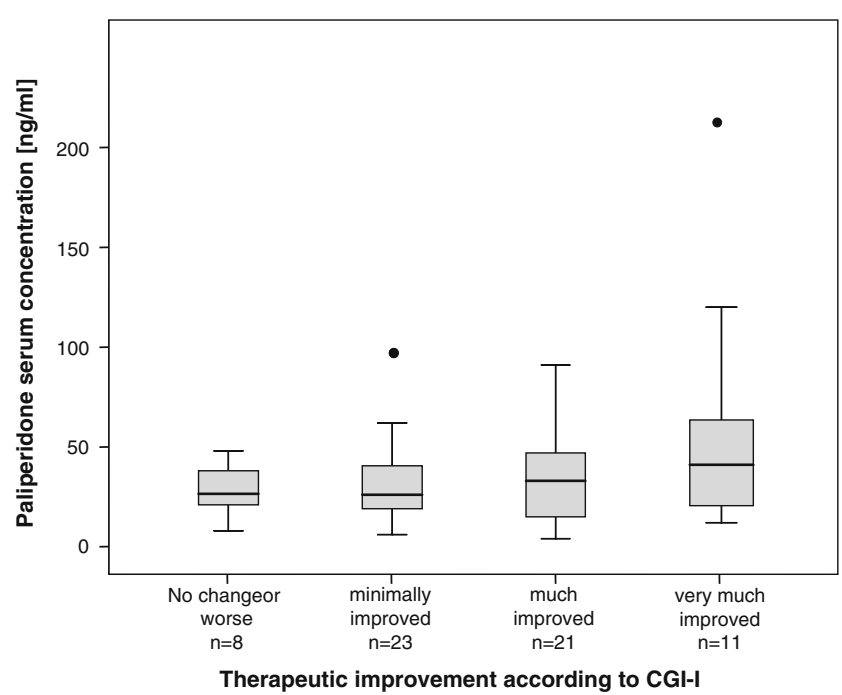

Fig. 2 Box plot of therapeutic improvement according to the Clinical Global Impressions scale on improvement $(C G I-I)$ and paliperidone serum concentrations in 63 patients who were receiving paliperidone as antipsychotic monotherapy 


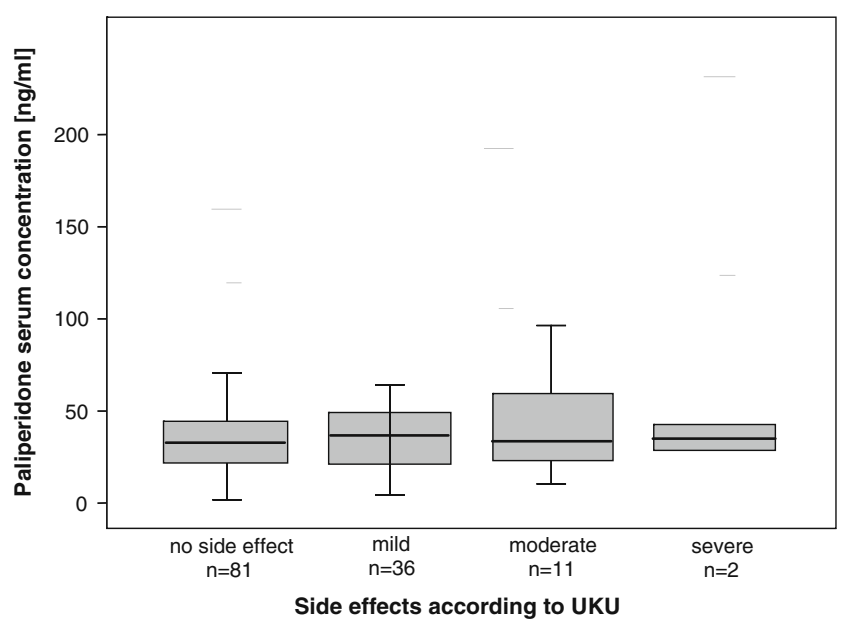

Fig. 3 Box plot of the tolerability (as measured by the UKU scale) and serum concentrations of paliperidone

In a separate analysis, we compared patient intra- and inter-individual variabilities in paliperidone serum concentrations with those of patients treated with risperidone using data from a single medical center (Mainz). A total of 30 patients were included in this analysis, 13 of whom received paliperidone and 17 risperidone. A mean of $4.3 \pm$ 1.5 (range: $3-8$ ) measurements were made on each patient, and a total of 134 samples were analyzed. Of this group of 40 patients, $45 \%$ were male and $55 \%$ female, and the mean age was $39.4 \pm 10.6$ years (Table 1 ). We found no significant differences between the coefficients of variance of serum concentrations. Intra-individual variability was $35 \pm 15 \%$ for paliperidone and $32 \pm 19 \%$ for the risperidone active moiety (Table 1).

\section{Discussion}

In this study we analyzed paliperidone serum concentrations in psychiatric patients treated with paliperidone, and we compared variabilities in the trough serum levels in patients receiving either paliperidone or risperidone as antipsychotic therapy. In patients receiving paliperidone as antipsychotic monotherapy and showing at least a much improvement level (according to the CGI-I scale), the 25th-75th percentiles of paliperidone serum levels were $20-52 \mathrm{ng} / \mathrm{ml}$. This range was almost identical with the recommended optimal plasma concentration of $20-60 \mathrm{ng} / \mathrm{ml}$ for the risperidone active moiety [9]. The intra-individual variabilities of trough serum concentrations were similar for paliperidone and risperidone plus 9-hydroxyrisperidone. The concentrations of risperidone and 9-hydroxyrisperidone measured in these patients are very similar to those reported previously by other investigators $[15,16]$.

Regarding the similar intra-individual variability in serum concentrations of paliperidone and risperidone, it should be noted that TDM measures trough levels. The ER formulation of paliperidone reduces the peak-to-trough fluctuations of drug concentrations in blood under steady state conditions [5]. According to the summary of product

Table 1 Mean \pm SD doses $(\mathrm{mg})$ and drug concentrations $(\mathrm{ng} / \mathrm{ml})$ and intra-individual coefficients of variance $(\mathrm{CV} \%)$ in patients treated under naturalistic conditions with either paliperidone or risperidone who were supervised by repeated therapeutic drug monitoring

\begin{tabular}{|c|c|c|c|}
\hline Variable & Paliperidone mean $\pm \mathrm{SD}$ & Risperidone mean $\pm \mathrm{SD}$ & $p$ value \\
\hline Number of patients & 13 & 17 & - \\
\hline Daily dose (mg/day) & $9.1 \pm 2.2$ & $5.1 \pm 2.3$ & $0.000^{\mathrm{a}}$ \\
\hline Number of samples per patient taken for TDM & $4.2 \pm 1.7$; range $3-8$; median 3 & $4.4 \pm 1.3$; range $3-7$; median 4 & $\mathrm{NS}^{\mathrm{b}}$ \\
\hline Age (years) & $37.1 \pm 12.4$ & $41.1 \pm 8.9$ & $\mathrm{NS}^{\mathrm{a}}$ \\
\hline Number of dose changes & $1.0 \pm 0.7 ;$ range $1-2 ;$ median 1 & $1.5 \pm 1.4 ;$ range $0-4 ;$ median 1 & $\mathrm{NS}^{\mathrm{b}}$ \\
\hline Gender (\% male) & 58 & 35 & $\mathrm{NS}^{\mathrm{b}}$ \\
\hline Total serum concentration $(\mathrm{ng} / \mathrm{ml})$ & $54.8 \pm 38.6$ & $31.6 \pm 14.4$ & $\mathrm{NS}^{\mathrm{b}}$ \\
\hline Dose-corrected serum concentration $(\mathrm{ng} / \mathrm{ml} / \mathrm{mg})$ & $6.2 \pm 4.1$ & $7.1 \pm 3.0$ & $\mathrm{NS}^{\mathrm{b}}$ \\
\hline $\begin{array}{l}\text { Dose and weight-corrected serum concentration } \\
{[(\mathrm{ng} / \mathrm{ml} / \mathrm{mg}) / \text { weight } \times 70 \mathrm{~kg}]}\end{array}$ & $5.0 \pm 3.6$ & $6.5 \pm 3.1$ & $\mathrm{NS}^{\mathrm{b}}$ \\
\hline CV\% of total serum concentration $(\mathrm{ng} / \mathrm{ml})$ & 32.2 & 33.8 & $\mathrm{NS}^{\mathrm{b}}$ \\
\hline $\mathrm{CV} \%$ of dose-corrected serum concentration $(\mathrm{ng} / \mathrm{ml} / \mathrm{mg})$ & 34.6 & 32.4 & $\mathrm{NS}^{\mathrm{b}}$ \\
\hline $\begin{array}{l}\text { CV\% of weight and dose-corrected serum concentration } \\
((\mathrm{ng} / \mathrm{ml} / \mathrm{mg}) / \text { weight } \times 70 \mathrm{~kg})\end{array}$ & 30.3 & 32.4 & $N S^{b}$ \\
\hline
\end{tabular}

TDM, Therapeutic drug monitoring; CV\%, coefficients of variance; NS, not significant

Where appropriate, values are given as the mean \pm standard deviation

${ }^{\mathrm{a}} t$ test

${ }^{\mathrm{b}}$ Mann-Whitney $U$ test 
characteristics (SPC), the peak-trough fluctuation index is $38 \%$ for paliperidone and $125 \%$ for the immediate-release formulation of risperidone [17]. Flattening of the pharmacokinetic profile can be obtained by decreasing peak levels, by increasing trough levels, or by both. Our measurements conducted under the naturalistic conditions of the TDM survey indicate that an increase in trough levels was unlikely since dose- and weight-corrected trough concentrations of paliperidone and risperidone plus the active metabolite were similar in patients receiving the ER formulation of paliperidone or the immediate-release formulation of risperidone. This result is consistent with data from a pharmacokinetic study on five healthy male subjects [6]. Moreover, a pharmacokinetic characterization of OROS and immediate-release amitriptyline has shown that acute doses of the OROS formulation affect primarily peak concentrations without affecting the elimination halflife of the antidepressant drug [18]. Similarly, our data provide evidence that steady state trough concentrations of paliperidone and risperidone are controlled by the metabolic and secretory capacities of the liver and the kidneybut not by the formulations of the drugs. In both drugs, the CYP3A4 isoenzyme is involved in the metabolic pathways [19]. For risperidone, CYP2D6 plays the predominant role in the formation of 9-hydroxyrisperidone [20]. Since CYP2D6 activity can be compromised due to a genetic deficiency or co-medication with a CYP2D6 inhibitor, the variability in plasma concentrations should be higher for risperidone than for paliperidone. However, when the "active moiety" of risperidone is taken into consideration and its elimination is compared with that of paliperidone, CYP2D6 becomes of minor importance [6] as concentrations of the active moiety of risperidone are not significantly different in individuals with an active or inactive CYP2D6 isoenzyme, respectively [21]. Another factor that contributes to pharmacokinetic variability of the two drugs is the efflux transporter P-glycoprotein (P-gp), which is expressed in several organs, especially in the intestinal epithelia and in the blood-brain barrier. Both risperidone and 9-hdroxyrisperidone/paliperidone are substrates of P-gp [22-24]. The expression of P-gp may vary due to genetic abnormalities and from inhibition or induction by co-medications. The unlikelihood of CYP3A4 and P-gp differing in their contribution to the elimination of either risperidone or paliperidone [17] provides a good explanation for why our observed variabilities in drug concentrations were not different for the two drugs.

In patients who were very much or much improved according to the CGI-score, the 25th-75th percentiles of paliperidone serum levels were $20-52 \mathrm{ng} / \mathrm{ml}$. In an earlier TDM study on amisulpride, we defined patients with at least a level of much improvement as "res- ponders" and thus calculated optimal plasma concentrations of amisulpride based on clinical effects [25]. In this study, however, the power of our data was not sufficient to evaluate a therapeutic range for paliperidone. Nevertheless, the 25 th- 75 th percentile range of serum levels was found to be similar to the clinically defined optimal target range $(20-52 \mathrm{ng} / \mathrm{ml})$ and thus was very similar to the therapeutic range reported for the sum of concentrations of risperidone plus 9-hydroxyrisperidone (20-60 $\mathrm{ng} / \mathrm{ml})$ [9]. This observation suggests that paliperidone and risperidone exhibit similar optimal serum concentrations. The $20-60 \mathrm{ng} / \mathrm{ml}$ range can be considered as a preliminary target range of paliperidone when applying TDM for treatment optimization and is slightly higher than the one derived from a recent positron emission tomography (PET) study with paliperidone [26]. In that study, paliperidone serum concentrations in the range between 16 and $27 \mathrm{ng} / \mathrm{ml}$ led to $65-80 \%$ striatal dopamine $D_{2}$ receptor occupancy, which is the $D_{2}$ occupancy range considered to be optimal for antipsychotic treatment [27-29]. PET studies on patients receiving risperidone also suggest that optimal (striatal) $\mathrm{D}_{2}$ receptor occupancy levels are achieved with serum concentrations of approximately $15-40 \mathrm{ng} / \mathrm{ml}[8,30]$ or probably somewhat higher [31]. The striatal median effective dose $\left(E_{50}\right)$ values calculated from PET studies are surprisingly similar for paliperidone $(6.65 \mathrm{ng} / \mathrm{ml})$ [26] and the risperidone active moiety $(6.87 \mathrm{ng} / \mathrm{ml})$ [30], which supports the view that the relationship between serum levels and $\mathrm{D}_{2}$ receptor occupancy is very similar for both compounds. Further PET studies on the relationship between serum levels, brain receptor occupancy, clinical effects, and side effects in larger patient samples are needed to resolve the slight discrepancies between the optimal therapeutic ranges suggested by PET studies and TDM surveys, respectively.

The side effects observed in our study were not significantly related to the doses or serum concentrations of paliperidone. This lack of correlation may be explained by the small number of patients. Side effects occurred only in a limited number of patients which reduces the power of the statistical analysis.

Our approach used a retrospective analysis of data without a fixed dose design, as we considered the latter to be the optimal approach to define therapeutic concentrations of a drug [9]. Therefore, this study has a number of limitations. Data were obtained from routine TDM surveys. Data on clinical improvement or side effects were missing for a significant number of patients and, therefore, the total number of patients who could be used in the various pharmacokinetic and pharmacodynamic analyses differed. The patients included for analysis were real life patients. As such, they were treated under naturalistic 
conditions which allowed co-medications which also affected clinical outcomes. The treatment duration of each patient receiving paliperidone as medication was not standardized. Variability due to pharmacokinetic interferences would seem to be unlikely since the data did not include patients under co-medications that may have given rise to interaction, namely, inducers or inhibitors of CYP3A4. Despite the marked limitations of our experimental conditions, the two antipsychotic drugs paliperidone and risperidone behaved in a rather similar manner in terms of the serum concentrations considered to be optimal when using TDM for dose optimization. A similarity was also observed for the variability of the trough levels of the drugs. We suggest that the clinically relevant differences between medication with paliperidone or risperidone, which differ in galenic formulation and phase-I metabolism, are likely attributable to the phase of absorption rather than to the phase of elimination of the drugs. Based on these results, we conclude that TDM is useful for treatment optimization of patients with paliperidone. The target range of $20-60 \mathrm{ng} / \mathrm{ml}$ recommended for risperidone [9] seems likely to be the target plasma concentration for paliperidone as well.

\section{References}

1. Kane J, Canas F, Kramer L et al (2007) Treatment of schizophrenia with paliperidone extended-release tablets: A 6-week placebo-controlled trial. Schizophr Res 90:147-161

2. Kramer M, Simpson G, Macciulis V et al (2007) Paliperidone extended-release tablets for prevention of symptom recurrence in patients with schizophrenia. J Clin Psychopharmacol 27(1):614

3. Leysen JE, Gommeren W, Enes D, Janssen PA (1988) Biochemical profile of risperidone, a new antipsychotic. J Pharmacol Exp Ther 247(2):661-670

4. Leysen JE, Janssen PM, Megens AA, Schotte A (1994) Risperidone: a novel antipsychotic with balanced serotonindopamine antagonism, receptor occupancy profile, and pharmacologic activity. J Clin Psychiatry 55[Suppl]:5-12

5. Karlsson P, Denker E, Nyberg S, Manaert E et al (2005) Pharmacokinetics, dopamine D2 and serotonin 5-HT2A-receptor occupancy and safety profile of paliperidone extended-release in healthy subjects: two open-label, single-dose studies. Clin Pharmacol Ther 79:P74

6. Vermeir M, Naessens I, Boom S, Clenton A (2008) Absorption, metabolism, and excretion of paliperidone, a new monoaminergic antagonist, in humans. Drug Metab Dispos 36:769-779

7. Heykants J, Huang ML, Mennens G, Woestenborghs R (1994) The pharmacokinetics of risperidone in humans: a summary. J Clin Psychiatry 55[Suppl]:13-17

8. Medori R, Mannaert E, Gründer G (2006) Plasma antipsychotic concentration and receptor occupancy, with special focus on risperidone long-acting injectable. Eur Neuropsychopharmacol 16 (4):233-240

9. Baumann P, Hiemke C et al (2004) The AGNP - TDM expert group consensus guidelines: therapeutic drug monitoring in psychiatry. Pharmacopsychiatry 37:243-265
10. Aravagiri M, Marder SR, Wirshing D, Wirshing WC (1998) Plasma concentrations of risperidone and its 9-hydroxy metabolite and their relationship to dose in schizophrenic patients: simultaneous determination by a high performance liquid chromatography with electrochemical detection. Pharmacopsychiatry 31 (3):102-109

11. Lane HY, Chiu WC, Chou JC, Wu ST, Su MH, Chang WH (2000) Risperidone in acutely exacerbated schizophrenia: dosing strategies and plasma levels. J Clin Psychiatry 61(3):209-214

12. Guy W (1976) Clinical global impressions. In: ECDEU assessment manual for psychopharmacology. DHEW Publ No ADM 76-338. National Institute of Mental Health, Rockville, pp 218-222

13. Lingjaerde O, Ahlfors UG, Bech P, Dencker SJ, Elgen K (1987) The UKU side effect rating scale. A new comprehensive rating scale for psychotropic drugs and a cross-sectional study of side effects in neuroleptic-treated patients. Acta Psychiatr Scand 334:1-100

14. Kirschbaum KM, Finger S, Vogel F, Burger R, Gerlach M, Riederer P, Hiemke C (2006) LC with column-switching and spectrophometric detection for determination of risperidone and 9OH-risperidone. Chromatographia 67:321-324

15. Riedel M, Schwarz MJ, Strassnig M, Spellmann I, Müller-Arends A, Weber K, Zach J, Müller N, Möller HJ (2005) Risperidone plasma levels, clinical response and side-effects. Eur Arch Psychiatry Clin Neurosci 255(4):261-268

16. Aichhorn W, Weiss U, Marksteiner J, Kemmler G, Walch T, Zernig G, Stelzig-Schoeler R, Stuppaeck C, Geretsegger C (2005) Influence of age and gender on risperidone plasma concentrations. J Psychopharmacol 19(4):395-401

17. SPC Invega. Available at: http://www.emea.europa.eu/humandocs/ PDFs/EPAR/invega/H-746-en6.pdf

18. Gupta SK, Shah JC, Hwang SS (1999) Pharmacokinetic and pharmacodynamic characterization of $\mathrm{OROS}^{\circledR}$ and immediaterelease amitriptyline. Br J Clin Pharmacol 48:71-78

19. Jung SM, Kim KA, Park JY (2005) Cytochrome P450 3A inhibitor itraconazole affects plasma concentrations of risperidone and 9-hydroxyrisperidone in schizophrenic patients. Clin Pharmacol Ther 78(5):520-528

20. Ereshefsky L (1996) Pharmacokinetics and drug interactions: updates for new antipsychotics. J Clin Psychiatry 57[Suppl 11]:12-25

21. Scordo MG, Spina E, Facciola G, Avenoso A, Johansson I, Dahl ML (1999) Cytochrome P450 2D6 genotype and steady state plasma levels of risperidone and 9-hydroxyrisperidone. Psychopharmacology 147:300-305

22. Doran A, Obach S, Yasgar AS, Zhang C (2005) The impact of p-glycoprotein on the disposition of drugs targeted for indications of the central nervous system: evaluation using the MDR1A/1B knockout mouse model. Drug Metab Dispos 33 (1): $165-174$

23. Gunes A, Spina E, Dahl ML, Scordo MG (2008) ABCB1 polymorphismus influence steady-state plasma levels of 9hydroxyrisperidone and risperidone active moiety. Ther Drug Monit 30(5):628-633

24. Kirschbaum KM, Henken S, Hiemke C, Schmitt U (2008) Pharmacodynamic consequences of P-glycoprotein-dependent pharmacokinetics of risperidone and haloperidol in mice. Behav Brain Res 188(2):298-303

25. Müller MJ, Regenbogen B, Härtter S, Eich FX, Hiemke C (2007) Therapeutic drug monitoring of optimizing amisulpride therapy in patients with schizophrenia. J Psychiatr Res 41:673679

26. Arakawa R, Ito H, Takano A, Takahashi H, Morimoto T, Sassa T, Ohta K, Kato M, Okubo Y, Suhara T (2008) Dose-finding study of paliperidone ER based on striatal and extrastriatal dopamine D2 
receptor occupancy in patients with schizophrenia. Psychopharmacology (Berl) 197(2):229-235

27. Farde L, Nordström AL, Wiesel FA, Pauli S, Hallidin C, Sedvall G (1992) Positron emission tomographic analysis of central $D_{1}$ and $\mathrm{D}_{2}$ dopamine receptor occupancy in patients treated with classical neuroleptics and clozapine. Relation to extrapyramidal side effects. Arch Gen Psychiatry 49:538-544

28. Kapur S, Zipursky R, Jones C, Remington G, Houle S (2000) Relationship between dopamine $\mathrm{D}(2)$ occupancy, clinical response, and side effects: a double-blind PET study of first-episode schizophrenia. Am J Psychiatry 157:514-520
29. Gründer G, Carlsson A, Wong DF (2003) Mechanism of new antipsychotic medications: occupancy is not just antagonism. Arch Gen Psychiatry 60(10):974-977

30. Nyberg S, Eriksson B, Oxenstierna G, Halldin C, Farde L (1999) Suggested minimal effective dose of risperidone based on PETmeasured D2 and 5-HT2A receptor occupancy in schizophrenic patients. Am J Psychiatry 156(6):869-875

31. Remington G, Mamo D, Labelle A, Reiss J, Shammi C, Mannaert E, Mann S, Kapur S (2006) A PET study evaluating dopamine D2 receptor occupancy for long-acting injectable risperidone. Am J Psychiatry 163(3):396-401 